\title{
Application of Redlich-Kister Modelto Measure and Predict Thermo Physical Properties of Binary Liquid Mixtures at Various Temperatures
}

\author{
R.Ramesh ${ }^{1}$ \\ Process Systems Engineering group (PSEG), Faculty \\ of Chemical \& Natural Resources Engineering, \\ Universiti Malaysia Pahang, \\ Gambang, MALAYSIA \\ Email:ramesh.redrouthu@gmail.com
}

\author{
K. Ramesh ${ }^{2}$ \\ Process Systems Engineering group (PSEG), Faculty \\ of Chemical \& Natural Resources Engineering, \\ Universiti Malaysia Pahang, \\ Gambang, MALAYSIA \\ Email: ramesh@ump.edu.my
}

\author{
K. Yusoh ${ }^{3}$ \\ Faculty of Chemical \& Natural Resources Engineering, \\ Universiti Malaysia Pahang, \\ Gambang, MALAYSIA \\ Email:kamal@ump.edu.my
}

\begin{abstract}
Study conducts in this research are Viscosities, $\eta$ and densities, of 1, 4-dioxane with Benzene at different mole fractions and various temperatures in the atmospheric pressure condition. From experimentations excess volumes, $V^{E}$, and deviation sin viscosities, $\Delta \eta$, of mixtures at infinite dilutions have been obtained. The measured systems exhibited positive values of $V_{m}{ }^{E}$ and negative values of $\Delta \eta$. The binary mixture 1 , 4 dioxane + Benzene show positive $V^{E}$ and negative $\Delta \eta$ with increasing temperatures. The outcomes clearly indicate that weak interactions present in mixture. It is mainly because of number and position of methyl groups exist in these aromatic hydrocarbons. These measured data tailored to the non-linear models to derive the binary coefficients. Standard deviations areconsidered between the fitted outcomes and the calculated data is helpful deliberate mixing behavior of the binary mixtures. It can conclude that in our cases, the data found with the values correlated by the corresponding models very well. The molecular interactions existing between the components and comparison of liquid mixtures also discussed.
\end{abstract}

Index Terms: Benzene, Density, Excess molar volume, Viscosity, Viscosity deviation, Oswald viscometer and OswaldSprengel Pyknometer.

\section{INTRODUCTION}

The quantitative viscosity, excess molar volume and density data of liquid mixtures are required to solve many engineering problems, involve in chemical separations, heat transfer, mass transfer, and fluid flow are important from practical and theoretical points of view, for understanding liquid theory. The low polarity of 1, 4 Dioxane is interesting to study with hydrocarbon mixtures, for the type of interaction between the components of binary systems.1,4 Dioxane commonly known as excellent aprotic solvent, it has a zero dipole movement and cyclic ether, that has an electron donor ability towards aromatic rings, it act like weak electron acceptors. 1, 4 Dioxane is used as a stabilizer in aluminium containers and solvent in inks and adhesives. There are few reports on density and viscosity data of 1,4 Dioxane with hydrocarbon mixtures $[1,2,12]$. In our earlier papers, we had studied thermo physical properties of binary systems $[2,12]$. In the present paper, it has been reported density ( $\rho)$ and viscosity ( $\eta$ ) of pure 1, 4 Dioxane, Benzene and Chloro Benzene for the binary system constituted by these two chemicals at entire range of composition and temperature $T=(303.15$ to 313.15$) \mathrm{K}$. With this data, the excess molar volume and deviation in viscosity have been computed.These results have been fitted to the Redlich-Kister and polynomial equations. The Redlich-Kister was used to correlate the excess volumes, $V^{\mathrm{E}}$, and deviations in viscosities, $\Delta \eta$, this analysis technique was used to derive the binary coefficients, estimated the standard deviation ( $\sigma$ ) between the experimental and calculated data [4]. The variation ofthese parameters with the composition and temperature of the mixtures has been discussed in terms of the molecular interactions in these mixtures. The effect of the number and position of the methyl groups in these aromatic hydrocarbons on molecular interactions in these mixtures has also been discussed. A literature search showed that no measurements have been previously reported by using Redlich-Kister model for the mixtures studied in this paper.

\section{EXPERIMENTAL PROCEDURE}

\section{A. Materials:}

1, 4-Dioxane, Benzene, ChloroBenzene, this were all supplied by $\mathrm{M} / \mathrm{s}$ E.Merck Ltd. With the stated purities better than $99 \%$, were stored over molecular sieves $(0.3 \mathrm{~nm}) .1$, 4 Dioxane with purity of $99 \%$ provided by Sigma-Aldrich Chemicals and it was used without further purification. To minimize the contact of these reagents with moist air, the products were kept in sealed bottles in a desiccator. The purity of the substances were determined by GLC. Densities and viscosities of pure substances and experimental values comparison with literature values are listed in Table $1[1,2,3$, and 4$]$. 


\section{B. Apparatus and Procedure:}

Measurements of the density, $\rho$, and the kinematic viscosity, $\gamma$, of pure liquids and their solutions were carried out using a Pycknometer and Oswald Viscometer and two integrated Pt 100 thermometers. The temperature in the cell was regulated $(0.001 \mathrm{~K}$ with a proportional temperature controller). The apparatus was first calibrated with triple distilled water. The uncertainties in density measurements were estimated to be $\left(2 \cdot 10^{-3} \mathrm{~kg} \cdot \mathrm{m}^{-3}\right.$ and. Further information about the experimental techniques has been the kinematic viscosities of the pure liquids and their mixtures were measured at (303.15, 308.15, and 313.15) $K$.The viscometer was filled with liquid or liquid mixtures, and its limbs were closed with Teflon caps taking due precaution to reduce evaporation losses. An electronic digital stopwatch with a readability of $0.01 \mathrm{~s}$ was used to flow time measurements. Experiments repeated a minimum of four times for all compositions, and the results were averaged. The caps of the limbs were removed during the measurement of flow times. The measured values of kinematic viscosity, $\gamma$, were converted to dynamic viscosity, $\eta$, after multiplication by the density. The reproducibility of dynamic viscosity was found to be within $(0.003 \mathrm{mPa} \cdot \mathrm{s}$. A thermostatically controlled, well-stirred water bath whose temperature was controlled to $(0.01 \mathrm{~K}$ was used for all the measurements. Conductivity measurements were carried out in a jacket containing a conductivity cell of cell constant $1.0 \mathrm{~cm}^{-1}$. Water was circulated in the jacket from thermostat, and the temperature was maintained within $\pm 0.01 \mathrm{~K}$ was used for all the measurements. The kinematic viscosity of solution $\gamma$ is given by

$$
\gamma=(a t-(b / t))
$$

Where $\gamma$ is the kinematic viscosity, $t$ is the flow time, the two constants a, and $b$ are the kinematic viscosities, $\gamma$, and densities. The uncertainty for the dynamic viscosity determination is estimated to be $\pm 0.5 \%$.

C. Standard Deviation

Standard deviation has calculated using the relationship.

$$
\begin{gathered}
\sigma=\underset{\sum}{\boldsymbol{\sum}}\left(\boldsymbol{V}_{\text {exp }}^{E}-\boldsymbol{V}^{E}{ }_{c a l}\right)^{2} /(\boldsymbol{N}-\boldsymbol{M})_{-}^{\overline{1} / 2} \\
\text { Where, N-Number of data points } \\
\mathrm{V}_{\text {exp }}^{\mathrm{E}}-\text { Experimental Excess molar volume } \\
\mathrm{V}_{\text {eal }}^{\mathrm{E}-\text { Calculated Excess molar volume }} \\
\mathrm{M}-\text { Number of coefficients }
\end{gathered}
$$

Table 1: Experimental Densities and Viscosities of Pure Liquids with Literature Values at 298.15K

\begin{tabular}{|l|l|l|l|l|l|}
\hline \multicolumn{5}{|l}{ Table 1: Experimental Densities and Viscosities of Pure Liquids with Literature Values at 298.15K } \\
\hline Component & & $\rho / \mathbf{g}^{-3}$ & \multicolumn{1}{l|}{$\boldsymbol{\eta}$ Pa s) } \\
\hline 1, 4-Dioxane & T(K) & Lit & Exp & Lit & Exp \\
\hline Benzene & 298.15 & 1.0280 & 1.0278 & 1.1664 & 1.1662 \\
\hline Chloro benzene & 298.15 & 0.8683 & 0.8684 & 0.6300 & 0.6289 \\
\hline
\end{tabular}


Table 2 Experimental Densities and viscosities of Benzene (1) + 1,4Dioxane (2) at 303.15, 308.15 and 313.15 K

\begin{tabular}{|c|c|c|c|c|c|c|c|c|c|}
\hline \multirow[b]{2}{*}{ X1 } & \multicolumn{3}{|c|}{$T / K=303.15$} & \multicolumn{3}{|c|}{$T / K=308.15$} & \multicolumn{3}{|c|}{$T / K=313.15$} \\
\hline & $\rho / \mathbf{g} \cdot \mathrm{cm}^{-3}$ & $\eta / \mathrm{mPa} \cdot \mathbf{s}$ & $V^{E} / \mathrm{cm}^{3} \cdot \mathrm{mol}^{-1}$ & $\rho / \mathbf{g} \cdot \mathrm{cm}^{-3}$ & $\eta / \mathbf{m P a} \cdot \mathbf{s}$ & $\begin{array}{l}V^{E} \\
/ \mathrm{cm}^{3} \cdot \mathrm{mol}^{-1}\end{array}$ & $\rho / \mathbf{g} \cdot \mathrm{cm}^{-3}$ & $\eta / \mathrm{mPa} \cdot \mathbf{s}$ & $\begin{array}{l}V^{E} \\
/ \mathrm{cm}^{3} \cdot \mathrm{mol}^{-1}\end{array}$ \\
\hline 0.0000 & 0.8649 & 0.5407 & 0.0000 & 0.8488 & 0.5221 & 0.0000 & 0.8418 & 0.5040 & 0.0000 \\
\hline 0.1047 & 0.8788 & 0.5807 & 0.3452 & 0.8599 & 0.5608 & 0.5928 & 0.8594 & 0.5463 & 0.9541 \\
\hline 0.2083 & 0.8943 & 0.6280 & 0.7459 & 0.8744 & 0.5963 & 1.1237 & 0.8668 & 0.5644 & 1.6854 \\
\hline 0.3109 & 0.9196 & 0.6665 & 1.3899 & 0.8807 & 0.6185 & 1.8691 & 0.8750 & 0.5923 & 2.4962 \\
\hline 0.4124 & 0.9306 & 0.6946 & 2.0456 & 0.8907 & 0.6420 & 2.6123 & 0.8830 & 0.6182 & 3.1244 \\
\hline 0.5128 & 0.9428 & 0.7426 & 2.7869 & 0.9026 & 0.6698 & 3.2546 & 0.8917 & 0.6379 & 3.7015 \\
\hline 0.6122 & 0.9640 & 0.7934 & 2.5869 & 0.9155 & 0.7072 & 3.0799 & 0.8985 & 0.6692 & 3.6013 \\
\hline 0.7106 & 0.9740 & 0.8534 & 2.2154 & 0.9357 & 0.7604 & 2.6899 & 0.9072 & 0.6947 & 3.2570 \\
\hline 0.8080 & 0.9971 & 0.9363 & 1.7458 & 0.9520 & 0.8282 & 2.2451 & 0.9273 & 0.7531 & 2.7245 \\
\hline 0.9045 & 1.0090 & 1.0133 & 1.1911 & 0.9793 & 0.9147 & 1.5369 & 0.9512 & 0.8243 & 1.7895 \\
\hline 1.0000 & 1.0271 & 1.0958 & 0.0000 & 1.0169 & 1.0094 & 0.0000 & 1.0128 & 0.9446 & 0.0000 \\
\hline
\end{tabular}

Table 3 Experimental Densities and viscosities of Chloro Benzene (1) + 1,4Dioxane (2)at 303.15, 308.15 and $313.15 \mathrm{~K}$

\begin{tabular}{|c|c|c|c|c|c|c|c|c|c|}
\hline \multirow[b]{2}{*}{ X1 } & \multicolumn{3}{|c|}{$T / K=303.15$} & \multicolumn{3}{|c|}{$\mathrm{T} / \mathrm{K}=\mathbf{3 0 8 . 1 5}$} & \multicolumn{3}{|c|}{$T / K=313.15$} \\
\hline & $\rho / \mathbf{g} \cdot \mathbf{c m}^{-3}$ & $\eta / \mathrm{mPa} \cdot \mathbf{s}$ & $V^{E} / \mathrm{cm}^{3} \cdot \mathrm{mol}^{-1}$ & $\rho / \mathbf{g} \cdot \mathbf{c m}^{-3}$ & $\eta / \mathrm{mPa} \cdot \mathbf{s}$ & $\begin{array}{l}V^{E} \\
/ \mathrm{cm}^{3} \cdot \mathrm{mol}^{-1}\end{array}$ & $\rho / \mathbf{g} \cdot \mathrm{cm}^{-3}$ & $\eta / \mathrm{mPa} \cdot \mathbf{s}$ & $\begin{array}{l}V^{E} \\
/ \mathrm{cm}^{3} \cdot \mathrm{mol}^{-1}\end{array}$ \\
\hline 0.0000 & 1.1366 & 0.7558 & 0.0000 & 1.1086 & 0.7206 & 0.0000 & 1.0822 & 0.6809 & 0.0000 \\
\hline 0.1047 & 1.1201 & 0.7673 & 0.5604 & 1.0944 & 0.7252 & 0.5371 & 1.0710 & 0.6952 & 0.4887 \\
\hline 0.2083 & 1.0937 & 0.7748 & 1.9872 & 1.0741 & 0.7371 & 1.6208 & 1.0618 & 0.7152 & 1.0183 \\
\hline 0.3109 & 1.0796 & 0.7878 & 2.3061 & 1.0660 & 0.7545 & 1.5553 & 1.0551 & 0.7289 & 0.7859 \\
\hline 0.4124 & 1.0721 & 0.8043 & 2.0160 & 1.0630 & 0.7744 & 1.4469 & 1.0495 & 0.7498 & 0.6886 \\
\hline 0.5128 & 1.0642 & 0.8436 & 1.7489 & 1.0513 & 0.8026 & 1.2423 & 1.0449 & 0.7810 & 0.4868 \\
\hline 0.6122 & 1.0562 & 0.8672 & 1.4765 & 1.0442 & 0.8150 & 1.0416 & 1.0393 & 0.7943 & 0.3647 \\
\hline 0.7106 & 1.0479 & 0.8929 & 1.2159 & 1.0389 & 0.8484 & 0.6675 & 1.0339 & 0.8273 & 0.2116 \\
\hline 0.8080 & 1.0401 & 0.9395 & 0.8978 & 1.0333 & 0.8786 & 0.3442 & 1.0268 & 0.8341 & 0.1953 \\
\hline 0.9045 & 1.0342 & 0.9652 & 0.4037 & 1.0258 & 0.9050 & 0.1027 & 1.0210 & 0.8534 & 0.0488 \\
\hline 1.0000 & 1.0271 & 1.0958 & 0.0000 & 1.0169 & 1.0094 & 0.0000 & 1.0100 & 0.9420 & 0.0000 \\
\hline
\end{tabular}


INTERNATIONAL JOURNAL OF

Table 4:Prediction of Excess molar volume, kinematic viscosities by Redlitch-Kister nonlinear model for 1, 4 Dioxane + Benzene at 303.15, 308.15 and $313.15 \mathrm{~K}$

\begin{tabular}{|c|c|c|c|c|c|c|}
\hline \multirow{2}{*}{$\mathbf{X}_{1}$} & $\begin{array}{l}V^{\mathrm{E}} \\
\text { (pred)(cc/gmole) }\end{array}$ & $\begin{array}{l}\Delta \eta \\
\text { (pred) }\end{array}$ & $\begin{array}{l}V^{\mathrm{E}} \\
\text { (pred)(cc/gmole) }\end{array}$ & $\Delta \eta($ pred $)$ & $\begin{array}{l}V^{\mathrm{E}} \\
\text { (pred)(cc/gmole) }\end{array}$ & $\Delta \eta($ pred $)$ \\
\hline & $\begin{array}{l}\text { (R-Kister) } \\
\text { T/K=303.15 }\end{array}$ & $\begin{array}{l}\text { (RKister) } \\
\text { T/K=303.15 }\end{array}$ & $\begin{array}{l}\text { (R-Kister) } \\
\text { T/K=308.15 }\end{array}$ & $\begin{array}{l}\text { (RKister) } \\
\text { T/K=308.15 }\end{array}$ & $\begin{array}{l}\text { (R-Kister) } \\
\text { T/K=313.15 }\end{array}$ & $\begin{array}{l}\text { (RKister) } \\
\text { T/K=313.15 }\end{array}$ \\
\hline 0.0000 & 0.0000 & 0.0000 & 0.0000 & 0.0000 & 0.0000 & 0.0000 \\
\hline 0.1047 & 0.5928 & -0.0152 & 0.5003 & -0.0123 & -0.0022 & -0.0067 \\
\hline 0.2083 & 0.8083 & -0.0304 & 0.9202 & -0.0280 & 0.5167 & -0.0223 \\
\hline 0.3109 & 1.8691 & -0.0469 & 1.6707 & -0.0525 & 1.8909 & -0.0502 \\
\hline 0.4124 & 2.5191 & -0.0689 & 2.5929 & -0.0830 & 3.1593 & -0.0776 \\
\hline 0.5128 & 2.9542 & -0.0854 & 3.0484 & -0.1044 & 3.6501 & -0.0910 \\
\hline 0.6122 & 3.2751 & -0.0876 & 2.9991 & -0.1106 & 3.9576 & -0.0986 \\
\hline 0.7106 & 2.8697 & -0.0768 & 2.9580 & -0.1067 & 4.9098 & -0.1142 \\
\hline 0.8080 & 2.8574 & -0.0566 & 2.9038 & -0.0902 & 5.6370 & -0.1208 \\
\hline 0.9045 & 1.8379 & -0.0265 & 1.7546 & -0.0474 & 3.5359 & -0.0737 \\
\hline 1.0000 & 0.0000 & 0.0000 & 0.0000 & 0.0000 & 0.0000 & 0.0000 \\
\hline
\end{tabular}

Table 5:Prediction of Excess molar volume, kinematic viscosities by Redlitch-Kister nonlinear model for 1, 4 Dioxane + Chloro Benzene at 303.15, 308.15 and 313.15 K

\begin{tabular}{|c|c|c|c|c|c|c|}
\hline \multirow{2}{*}{$\mathbf{X}_{1}$} & $\begin{array}{l}V^{\mathrm{E}} \\
\text { (pred)(cc/gmole) }\end{array}$ & $\begin{array}{l}\Delta \eta \\
\text { (pred) }\end{array}$ & $\begin{array}{l}\mathrm{V}^{\mathrm{E}} \\
\text { (pred)(cc/gmole) }\end{array}$ & $\Delta \eta($ pred $)$ & $\begin{array}{l}\mathrm{V}^{\mathrm{E}} \\
\text { (pred)(cc/gmole) }\end{array}$ & $\Delta \eta($ pred) \\
\hline & $\begin{array}{l}\text { (R-Kister) } \\
\text { T/K=303.15 }\end{array}$ & $\begin{array}{l}\text { (RKister) } \\
\text { T/K=303.15 }\end{array}$ & $\begin{array}{l}\text { (R-Kister) } \\
\text { T/K=308.15 }\end{array}$ & $\begin{array}{l}\text { (RKister) } \\
\text { T/K=308.15 }\end{array}$ & $\begin{array}{l}\text { (R-Kister) } \\
\text { T/K=313.15 }\end{array}$ & $\begin{array}{l}\text { (RKister) } \\
\text { T/K=313.15 }\end{array}$ \\
\hline 0.0000 & 0.0000 & 0.0000 & 0.0000 & 0.0000 & 0.0000 & 0.0000 \\
\hline 0.1047 & 0.6155 & -0.0275 & 0.5939 & -0.0280 & 0.0916 & -0.0151 \\
\hline 0.2083 & 1.8173 & -0.0445 & 1.4300 & -0.0385 & 0.9841 & -0.0172 \\
\hline 0.3109 & 2.4007 & -0.0705 & 1.7156 & -0.0516 & 1.2546 & -0.0292 \\
\hline 0.4124 & 2.1594 & -0.0999 & 1.5077 & -0.0736 & 1.1503 & -0.0472 \\
\hline 0.5128 & 1.6546 & -0.1003 & 1.1811 & $\mathbf{- 0 . 0 7 7 7}$ & 1.0232 & -0.0453 \\
\hline 0.6122 & 1.3692 & -0.0813 & 0.9418 & -0.0656 & 0.7853 & -0.0308 \\
\hline 0.7106 & 1.2613 & -0.0869 & 0.7190 & -0.0697 & 0.6366 & -0.0390 \\
\hline 0.8080 & 0.9633 & -0.1168 & 0.3926 & -0.0923 & 0.5709 & -0.0710 \\
\hline 0.9045 & 0.3693 & $\mathbf{- 0 . 0 8 9 7}$ & 0.0745 & -0.0710 & 0.1701 & -0.0618 \\
\hline 1.0000 & 0.0000 & 0.0000 & 0.0000 & 0.0000 & 0.0000 & 0.0000 \\
\hline
\end{tabular}


Table 6Parameters of studiedRedlitch-Kister nonlinear model, constants and standard deviations ( $\sigma$ ) for Excess Volume of 1, 4 Dioxane + Benzene and 1, 4 Dioxane + Chloro Benzene, at 303.15, 308.15 and 313.15 K

\begin{tabular}{|c|c|c|c|c|c|c|c|c|}
\hline $\begin{array}{c}\text { Temperature } \\
(\mathrm{T} / \mathrm{K}) \\
\mathrm{T} / \mathrm{K} \\
\end{array}$ & $\mathrm{A}_{1}$ & $\mathrm{~A}_{2}$ & $\mathrm{~A}_{3}$ & $\mathrm{~A}_{4}$ & $\mathrm{~A}_{5}$ & $\mathrm{~A}_{6}$ & $\mathrm{~A}_{7}$ & $\sigma$ \\
\hline \multicolumn{9}{|c|}{ Benzene (1) $+1,4$ Dioxane (2) } \\
\hline 303.15 & -56.509 & -27.653 & 66.619 & 26.913 & -15.736 & 0.7609 & 5.6556 & 0.2113 \\
\hline 308.15 & -67.92 & -34.501 & 74.331 & 30.247 & -18.49 & 4.2666 & 12.104 & 0.2120 \\
\hline 313.15 & -87.369 & -102.92 & 76.667 & 98.355 & -3.6776 & 5.0706 & 14.481 & 0.8709 \\
\hline \multicolumn{9}{|c|}{ Chloro Benzene (1) + 1,4Dioxane (2) } \\
\hline 303.15 & 19.75 & -9.324 & -44.93 & 18.79 & 18.32 & -9.362 & 6.85 & 0.2217 \\
\hline 308.15 & 11.15 & 4.818 & -26.09 & 1.381 & 10.04 & 6.102 & 4.877 & 0.1487 \\
\hline 313.15 & -87.369 & -102.9 & 76.667 & 98.355 & -3.677 & 5.0706 & 15.481 & 0.1391 \\
\hline
\end{tabular}

Table 7Parameters of studiedRedlitch-Kister nonlinear model, constants and standard deviations ( $\sigma$ ) for Viscosity Deviationof 1, 4 Dioxane + Benzene and 1, 4 Dioxane + Chloro Benzene, at 303.15, 308.15 and $313.15 \mathrm{~K}$

\begin{tabular}{|c|c|c|c|c|c|c|c|c|c|c|}
\hline $\begin{array}{c}\text { Temperature } \\
(\mathrm{T} / \mathrm{K})\end{array}$ & $\mathrm{A}_{1}$ & $\mathrm{~A}_{2}$ & $\mathrm{~A}_{3}$ & $\mathrm{~A}_{4}$ & $\mathrm{~A}_{5}$ & \multicolumn{2}{c|}{$\mathrm{A}_{6}$} & $\mathrm{~A}_{7}$ & $\sigma$ \\
\hline \multicolumn{7}{|c|}{ Benzene (1)+ 1,4Dioxane (2) } \\
\hline 303.15 & 1.328 & 0.0171 & -1.5746 & 0.2169 & 0.5935 & -0.2341 & -0.3483 & 0.005 \\
\hline 308.15 & 1.3354 & 0.6588 & -1.3364 & -0.3553 & 0.4108 & -0.3047 & -0.4107 & 0.002 \\
\hline 313.15 & 1.842 & 1.8177 & -1.5655 & -1.6702 & 0.0816 & -0.1671 & -0.3602 & 0.011 \\
\hline 303.15 & 4.434 & 2.343 & -5.013 & 2.612 & 0.981 & 0.255 & -0.408 & 0.020 \\
\hline 308.15 & 3.841 & 1.527 & -4.342 & -1.654 & 0.811 & 0.116 & -0.314 & 0.015 \\
\hline 313.15 & 3.451 & 1.8 & -4.045 & -2.032 & 0.778 & 0.224 & -0.187 & 0.012 \\
\hline
\end{tabular}


The excess molar volumes, $V^{E}$, dynamic viscosity, $\eta$, and molar refraction changes of mixing were calculated from experimental values using the following expressions.

$\boldsymbol{V}^{E}=\boldsymbol{V}_{M}-\sum_{i=1}^{n} \boldsymbol{X}_{i} \boldsymbol{V}_{i}$

Where $V_{M}$ is the molar volume of the mixture, $\eta$ is the dynamic viscosity, and $V_{i}$ is Molar volume.

The variation of excess volumes with the mole fraction of Benzene and ChloroBenzene with 1, 4 Dioxane at (303 $.15,308.15$ and 313.15) $\mathrm{K}$ are represented in Figure 1 and Figure 2.

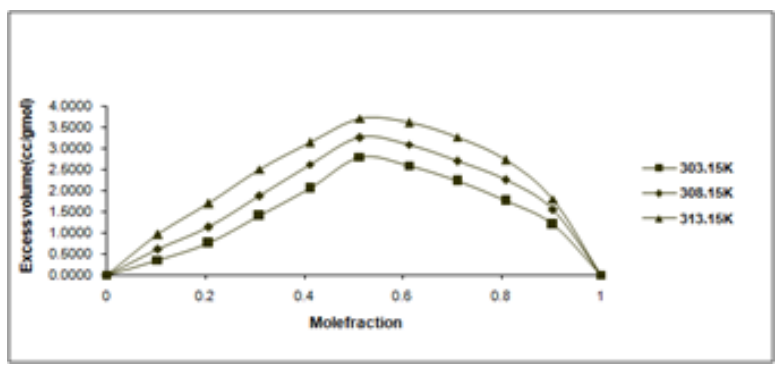

Fig.1. Excess molar volume $\left(V^{E}\right)$ for 1, 4 Dioxane + Benzene at 303.15, 308.15 and 313.15 $\mathrm{K}$

The sign of excess volume of a system depends on the relative magnitude of expansion/contraction on mixing of two liquids. If the factors causing expansion dominate the contraction factors, the $\left(\mathrm{V}^{\mathrm{E}}\right)$ becomes positive.

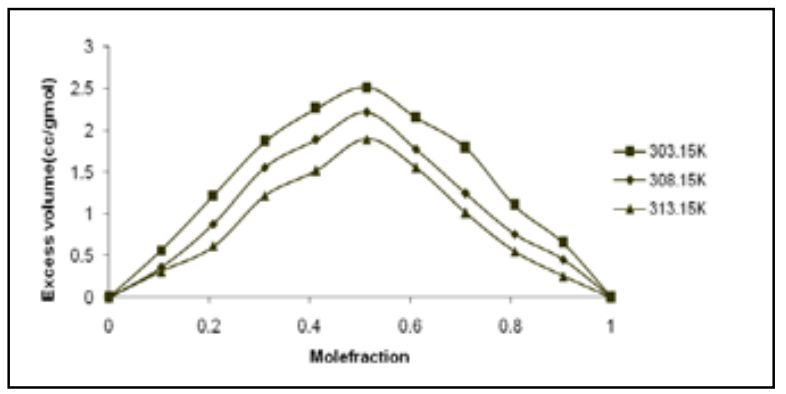

Fig.2. Excess molar volume $\left(V^{\mathrm{E}}\right)$ for 1,4 Dioxane + Chloro Benzene at 303.15, 308.15 and 313.15 K

On the other hand if the contraction factors dominate the expansion factors, then $V^{E}$ become negative. The factors that are responsible for expansion in volume are as follows, i. Loss of dipolar association, ii. The geometry of molecular structure, which does not allow fitting of one component into other component, iii. Steric hindrance opposes proximity of the constituent molecules. The negative $V^{E}$ values arise due to dominance of the following factors. i. Chemical interaction between constituent chemicals. ii. Accommodation of molecules of one component into the interstitials of the molecules of the other component $[8,9]$. iii. Geometry of the molecular structure that favors fitting of the component molecules with each other $[9,10,12]$. The negative $V^{E}$ values in the mixtures under study indicates that interactions between molecules of the mixtures are stronger than interactions between molecules in the pure liquids and that associative force dominate the behavior of the solution.

$$
\Delta \eta=\eta-\sum_{i=1}^{n} x_{i} \eta_{i}
$$

Where $(\Delta \eta)$ is the viscosity deviation of the mixture, $\eta$ is the dynamic viscosity.

The results of variation in viscosity deviations of binary systems consisting of Benzene and Chloro Benzene with 1, 4 Dioxane at temperatures of $303.15 K, 308.15 K$, and $313.15 \mathrm{~K}$ are represented in figure 3 and 4 .

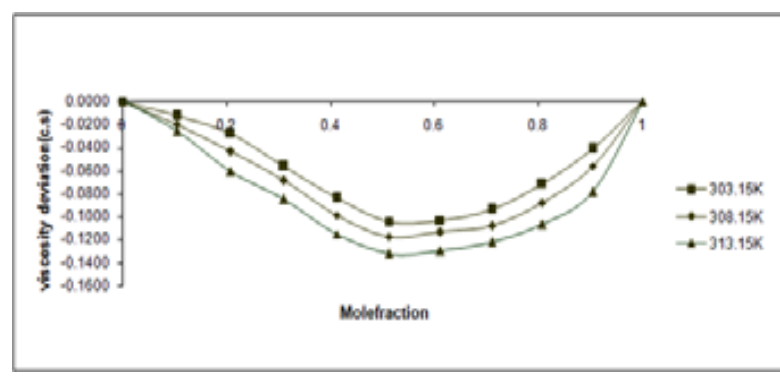

Fig.3. Deviation in viscosity $(\Delta \eta)$ for 1,4 Dioxane + Benzene at 303.15, 308.15 and $313.15 \mathrm{~K}$

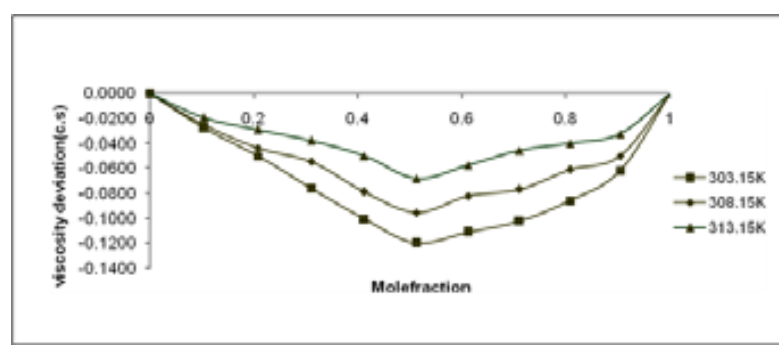

Figure 4. Deviation in viscosity $(\Delta \eta)$ for 1,4Dioxane + Chloro Benzene at 303.15, 308.15 and $313.15 \mathrm{~K}$

This result shows negative deviations $[6,7,11,12]$ over the entire range of mole fraction. The viscosity of the mixture strongly depends on the entropy of mixture, which related with liquid's structure and enthalpy. It will consequently with molecular interactions between the components of the mixtures. Therefore, the viscosity deviation depends on molecular interactions as well as on the size and shape of the molecules.

\section{CONCLUSION}

In the present study of Viscosities $(\eta)$ and Excess molar volume $\left(V^{E}\right)$, for the binary liquid mixture of 1,4 Dioxane + Benzene + ChloroBenzene system was found as a function of mole fraction at atmospheric pressure and at temperatures of $303.15 \mathrm{~K}, 308.15 \mathrm{~K}$, and $313.15 \mathrm{~K}$. The excess values of the mixtures show a systematic change with increasing temperature. With an increase in temperature, the intermolecular interactions between molecules become weak. 1, 4 Dioxane is repulse towards the Benzenering in Benzene and it forms dipole-dipole bond .In this case, the force between unlike molecules is lesser than the force between like molecules 
in mixtures. It can be concluded that the positive excess molar volumes and negative deviations viscosity due to weak molecular interactions in mixtures. Viscosity and density of the binary mixture and the Redlitch-Kister model is very well suited for correlating Kinematic viscosity and Excess molar volumes of the binary mixture with minimum standard deviation in present study and it is far superior to the other predictive models

\section{ACKNOWLEDGMENT}

The authors would like to thank Faculty of Chemical \& Natural Resources Engineering, University Malaysia Pahang, for providing continuous laboratory facility.

\section{REFERENCES}

1. Martin Contreras S. 2001 Densities and Viscosities of Binary Mixtures of 1, 4-Dioxane with 1-Propanol and 2-Propanol at (25, 30, 35, and 40) oC J. Chem. Eng. Data, 46, 1149 - 1152.

2. R.Ramesh. A.Hisyam. K.Ramesh. Measurement and Prediction of Thermo Physical Properties of Binary Liquid Mixtures at Various Temperatures Using Mc Allister Model, IJES., 3, 68-74 (2014)

3. JouybanA.,KhoubnasabjafariM.,Vaezgharamaleki., Z.,Fekari Z. and Jr.Acree, W.E., Calculation of the viscosity of binary liquid mixture at various temperatures using Jouyban - Acree model, Chemical and Pharmaceutical Bulletin., 53, 519-523 (2005)

4. Redlich O. and Kister A.T., Algebraic representation of thermodynamic properties and the classification of solutions, Ind. Eng. Chem, 40, 345-349 (1948)

5. Vadamalar R. Mani D. and Balakrishnan, Ultrasonic Study of Binary Liquid Mixtures of Methyl Methacrylate with Alcohols, Res.J.Chem.Sci., 1(9), 79-82 (2011)

6. S. Senthil Raja and T. R Kubendran, 2004. Viscosities and Densities of Binary Mixtures of 1,4 - Dioxane, Carbon Tetrachloride, and Butanol at 303.15K, 308.15K, and 313.15K J. Chem. Eng. Data, 49, 421-425.

7. Baskaran.R. and Kubendran.T.R, 2007.Intermolecular Interactions in Binary Liquid Mixtures, Of Anisaldehyde with Nitrobenzene and Ethyl Benzene by Ultrasonic Measurements at $(303.15,313.15$ and 313.15) K, Chemical Physics Research Journal, 2: 1-14.

8. Fabio Comelli, Romolo Francesconi, Adriana Bigi, and Katia Rubini, 2006. Excess Molar Enthalpies, Molar Heat Capacities, Densities, Viscosities, and Refractive Indices of Dimethyl Sulfoxide + Esters of Carbonic Acid at $308.15 \mathrm{~K}$ and Atmospheric Pressure J. Chem. Eng. Data , 51, 665-670

9. Francesconi, R.; Bigi, A.; Rubini, K.; Comelli, F. 2005 Excess enthalpies, heat Capacities, densities, viscosities, and refractive indices of dimethyl sulfoxide + three aryl alcohols at $308.14 \mathrm{~K}$ and atmospheric pressure. J. Chem. Eng. Data, 50, 1932-1937.

10. Hiannie ,D.; Suryadi, I. 2005 Density and viscosity of several aldehydes fragrance compounds in their binary mixtures with ethano at 298.15, 308.15 and 318.15 K. J. Chem. Eng. Data, 50, 2003- 2007.

11. S. Senthil Raja and T. R Kubendran, 2004. Viscosities and Densities of Binary Mixtures of 1,4 Dioxane, Carbon Tetrachloride, and Butanol at 303.15K, 308.15K, and 313.15K J. Chem. Eng. Data, 49, 421-425.

12. R.Ramesh.A.Hisyam.A.Z. Sulaiman., K.Ramesh,"Measurement and Predict Thermo Physical PropertiesofBinary Liquid Mixtures at Various Temperatures Using Redlich-Kister Model" Chemical Engineering and Science, 2014, Vol. 2, No. 2, 18-23. 